\title{
Influence of occupations of professionally ap- plied physical culture at DSTU on the formation of a specialist in the agro-industrial complex
}

\author{
Nikolay Ryzhkin ${ }^{1, *}$, Tatiana Tumasyan ${ }^{1}$, Olga Brovashova $^{1}$, Elena Nemtseva ${ }^{1}$, and Anna \\ Ivanova $^{1}$ \\ ${ }^{1}$ Don State Technical University, 1, Gagarin Sq., 344003 Rostov-on-Don, Russia
}

\begin{abstract}
The significant changes that have taken place in the life of modern society require a radical reorientation of the forms, means and methods of teaching, the search for innovative ways to improve the training of young specialists. The training of students in agricultural specialties is no exception. Professiographic analysis of the physical condition of an agrarian makes it possible to identify the optimal set of means and methods of physical culture to acquire the qualities necessary in this profession.
\end{abstract}

\section{Introduction}

Rostov Region is one of the largest agro-industrial centers in Russia with a high level of development of agriculture and food processing industry.

The concept for the development of the agro-industrial complex of the Rostov region determines the strategic goals, objectives, priorities and directions for the development of agriculture, food and processing industries, aimed at constantly improving the level and quality of life of the rural population, as well as sustainable development of rural areas. The implementation of the Concept is aimed at the formation and development of economic and institutional conditions for sustainable and dynamic development of the agro-industrial complex of the region. The main ideas of the Concept are based on the effective use of the resource and market potential of the agro-industrial complex of the Rostov region in order to meet the current needs of the population for safe, high-quality food products from agricultural production and the food industry.

Today Rostov-on-Don is the largest science center in the South of Russia. Thousands of young people study in 14 educational institutions of higher education in the region. The higher school of the Rostov region, headed by the flagship university - the Don State Technical University (hereinafter - DSTU) is the hallmark of science and education of the Don, which has accumulated a rich heritage.

The significant changes that have taken place in the life of modern society require a radical reorientation of the forms, means and methods of teaching, the search for innovative ways to improve the training of young specialists. The training of students in agricultural specialties is no exception.

\footnotetext{
* Corresponding author: olivka1103@yandex.ru
} 
To ensure the high quality of general education, it is required, inter alia, to improve the conditions and organization of training in educational organizations. The staff of the Department of Physical Education of DSTU makes every effort to ensure that all formulated plans and tasks set for teachers were successfully implemented. That should ensure high results in the physical, spiritual and moral education of young people. Currently, the problem of the effectiveness of teaching methods and technologies is urgent. itdue to the fact that in order to improve the quality of education, new requirements are being put forward for modern occupation - the use of various forms and systems of education, their non-standard combination with each other. In the context of education, individualization is the personalization of educational trajectories, that is, the formation of individual learning trajectories for the requests of potential customers.

It is necessary to create conditions for the upbringing of a harmoniously developed and socially responsible person on the basis of the spiritual and moral values of the peoples of the Russian Federation, historical and national-cultural traditions. Development of a modern infrastructure for training highly qualified specialists and workers in accordance with modern standards and advanced technologies in order to eliminate the shortage of workers.

In market conditions, it is important to provide a new approach to the professional development of an individual, based on a combination of mobility and stability. We believe that professional-applied physical education at the university is extremely necessary for future specialists of the agro-industrial faculty. Good physical fitness, endurance, dexterity, speed and other basic motor qualities - seem to be one of the guarantees of success in the future professional activity of a student, who is able to ensure effective management of the agro-industrial complex.

\section{Materials and methods}

The goal is to search for new methods of influence, to improve the quality of the competencies of future specialists in the agro-industrial complex for the upcoming professional activities through the design and implementation of professionally applied physical training (hereinafter - PPPP) of students of the agroindustrial faculty of DSTU, directed development of their social and professional competence.

To solve the tasks set before the authors of this work, a complex of scientific methods was used, which included: analysis of pedagogical, psychological and scientific-methodical literature; observation; diagnostic methods (testing); pedagogical experiment; methods of mathematical statistics for processing experimental data. The analysis includes data obtained as a result of a study among 1-3 year students of the Agroindustrial Faculty of Don State University. The hypothesis of the research is that the system of formation of professionally applied physical training of DSTU students in physical education classes will improve the quality of their preparation for high-quality productive work.

The expediency of the study lies in the search for new methods of influencing the physical qualities necessary in the future professional activities of students of the Agroindustrial Faculty.

Approbation and implementation of the research results were carried out throughout the entire period of 2017-2020, the work of the authors-teachers of the Department of Physical Education, DSTU.

The results of the study were discussed at meetings of the Department of Physical Education of DSTU and Academic Council of the Faculty of the Institute of Physical Culture and Sports, where they received approval and support.

Professiographic analysis of the physical condition of an agrarian makes it possible to identify the optimal set of means and methods of physical culture to acquire the qualities necessary in this profession: 
1. Large physical activity

2. Uniformity of actions

3. Long exposure to air

4. Strength

5. Endurance

6. Accuracy and responsiveness

7. Concentration of attention

The relevance of this study is due to the study of materials and the development of programs aimed at improving the adaptive potential of students and the qualitative balance of physical qualities that directly affect the future profession.

The expediency of the study lies in the search for new methods of influencing the physical qualities necessary in the future professional activities of students of the Agroindustrial Faculty.

The analysis includes the results of regular testing of students of the Agroindustrial Faculty.

The age of the subjects was from 17 to 21 years. The average age is 19 . Both male and female students participated in the testing.

The following standards were taken as a basis (tables 1):

Table 1. Data at the beginning of the experiment (2017)

\begin{tabular}{|l|l|l|}
\hline & \multicolumn{1}{|c|}{ Young men } & \multicolumn{1}{|c|}{ Girls } \\
\hline 1 & Run $60 \mathrm{~m}$ & Run $60 \mathrm{~m}$ \\
\hline 2 & Incline & Incline \\
\hline 3 & High bar pull-up & Hanging pull-up on a low bar \\
\hline 4 & $\begin{array}{l}\text { Flexion / extension of the arms in the } \\
\text { lying position }\end{array}$ & $\begin{array}{l}\text { Flexion / extension of the arms in the } \\
\text { lying position }\end{array}$ \\
\hline 5 & Standing long jump & Standing long jump \\
\hline 6 & Raising the torso & Raising the torso \\
\hline 7 & Running $3000 \mathrm{~m}$ & Run $2000 \mathrm{~m}$ \\
\hline
\end{tabular}

The frequency of the study is from March 2017 to January 2020, monthly, excluding the vacation period.

The research was carried out by the teachers of the Department of Physical Education, Don State Technical University.

The experiment involved 1-3 year students of the Agroindustrial Faculty of the Don State Technical University. The number of the tested was 180 people.

The standards of the RLD complex were taken as a basis for assessing the physical fitness of students: a gold sign, a silver, a bronze one. According to the age of student youth, this is the 6th stage of the TRP complex.

The research algorithm is as follows:

1. Identification of the level of preparedness among 1st year students through testing of physical qualities necessary in the future professional activities of students of the Agroindustrial Faculty.

2. Analysis of the information received.

3. Justification and development of a program aimed at the formation and development fundamental physical qualities necessary in the future profession.

4. Interim tests with subsequent adjustments.

5. Analysis of the information received.

6. Final testing.

7. Conclusions and recommendations. 
Research group of the department "Physical education" DSTU a system of physical activity was tested and proposed to improve professional-applied physical training, taking into account the year of study and future specialization (in this case, agricultural).

It was suggested:

1. Conduct regular follow-up tests.

2. Organize the storage of tests in electronic form and in paper.

3. Conduct regular monitoring of the dynamics of results among students of the Agroindustrial Faculty.

4. Select complexes of exercises aimed at improving lagging physical qualities, improving students' working capacity and keeping it high.

The percentage of tests completed by students of the Agroindustrial Faculty (tables 2):

Table 2. Data at the beginning of the experiment (March 2017)

\begin{tabular}{|l|l|l|l|}
\hline \multicolumn{1}{|c|}{ Young men } & $\begin{array}{l}\text { Percentage of } \\
\text { completion }\end{array}$ & \multicolumn{1}{|c|}{ Girls } & $\begin{array}{c}\text { Percent } \\
\text { age of } \\
\text { complet } \\
\text { ion }\end{array}$ \\
\hline Run $60 \mathrm{~m}$ & $74 \%$ & Run $60 \mathrm{~m}$ & $62 \%$ \\
\hline Incline & $61 \%$ & Incline & $81 \%$ \\
\hline High bar pull-up & $64 \%$ & $\begin{array}{l}\text { Hanging pull-up on a low } \\
\text { bar }\end{array}$ & $43 \%$ \\
\hline $\begin{array}{l}\text { Flexion / extension of the } \\
\text { arms in the lying position }\end{array}$ & $69 \%$ & $\begin{array}{l}\text { Flexion / extension of the } \\
\text { arms in the lying position }\end{array}$ & $42 \%$ \\
\hline Standing long jump & $72 \%$ & Standing long jump & $54 \%$ \\
\hline Raising the torso & $67 \%$ & Raising the torso & $61 \%$ \\
\hline Running 3000 m & $43 \%$ & Run 2000 m & $32 \%$ \\
\hline
\end{tabular}

Note: the number of students who did not cover the distance of $3000 \mathrm{~m}$ is $7 \%$, the number of students who did not cover the distance of $2000 \mathrm{~m}$ is $9 \%$.

Received data as a result of testing, we can draw the following conclusions:

1. The level of strength exercises, speed running, long jump from the spot is higher among young men.

2. The level of performance of flexibility exercises, on the contrary, is higher among girls.

3. Such quality as endurance (running at $2000 \mathrm{~m}$ for girls and $3000 \mathrm{~m}$ for boys) is at a very low level for both boys and girls. This standard has a percentage of students did not cover the entire distance and, accordingly, did not complete the test.

The proposed complex of methodological recommendations affecting the development of physical qualities required to improve professionally applied physical fitness includes several stages.

All stages of training are characterized by a high degree of versatility with the use of a wide range of training means.

The purpose of training is to create conditions for better results in fulfilling standards, to help improve functional and coordination readiness with the help of versatile and diverse loads.

The research group proposed to conduct training sessions in the form of circuit training. Circuit training includes:

- warm-up complex

- a set of exercises aimed at developing one of the qualities (speed, strength, endurance, flexibility, coordination)

- a set of exercises aimed at improving one of the qualities (speed, strength, endurance, flexibility, coordination). 
The load in circuit training varies depending on the fitness and condition of the trainees.

The innovation of this technique lies in the variety of exercises, the use of a variety of sports equipment, combination and variability. As a result, the classes are not similar to one another - as a result, monotony does not arise. Classes are interesting, emotional, and at the same time, students receive the planned load without noticing it.

Based on the results of interim testing, it is obvious that the right path was chosen and that the proposed technique is effective (see Table 3). Adjustments were made to the load dosage and the experiment continued.

Table 3. Data at December 2018 year

\begin{tabular}{|l|l|l|l|}
\hline \multicolumn{1}{|c|}{ Young men } & $\begin{array}{c}\text { Percentage of } \\
\text { completion }\end{array}$ & \multicolumn{1}{|c|}{ Girls } & $\begin{array}{c}\text { Percenta } \\
\text { ge of } \\
\text { completi } \\
\text { on }\end{array}$ \\
\hline Run 60 m & $77 \%$ & Run $60 \mathrm{~m}$ & $64 \%$ \\
\hline Incline & $65 \%$ & Incline & $81 \%$ \\
\hline High bar pull-up & $67 \%$ & $\begin{array}{l}\text { Hanging pull-up on a low } \\
\text { bar }\end{array}$ & $46 \%$ \\
\hline $\begin{array}{l}\text { Flexion / extension of the } \\
\text { arms in the lying position }\end{array}$ & $73 \%$ & $\begin{array}{l}\text { Flexion / extension of the } \\
\text { arms in the lying position }\end{array}$ & $44 \%$ \\
\hline Standing long jump & $75 \%$ & Standing long jump & $56 \%$ \\
\hline Raising the torso & $72 \%$ & Raising the torso & $69 \%$ \\
\hline Running 3000 m & $46 \%$ & Run 2000 m & $37 \%$ \\
\hline
\end{tabular}

Note: the number of students who did not overcome the distance of $3000 \mathrm{~m}-5 \%$, the number of students who did not overcome the distance of $2000 \mathrm{~m}-8 \%$.

The percentage of tests completed by students of the Agroindustrial Faculty (tables 4).

Table 4. Data at December 2019 year

\begin{tabular}{|l|l|l|l|}
\hline Young men & $\begin{array}{l}\text { Percentage of } \\
\text { completion }\end{array}$ & Girls & $\begin{array}{l}\text { Percent } \\
\text { age of } \\
\text { complet } \\
\text { ion }\end{array}$ \\
\hline Run $60 \mathrm{~m}$ & $81 \%$ & Run $60 \mathrm{~m}$ & $73 \%$ \\
\hline Incline & $69 \%$ & Incline & $84 \%$ \\
\hline High bar pull-up & $73 \%$ & $\begin{array}{l}\text { Hanging pull-up on a low } \\
\text { bar }\end{array}$ & $52 \%$ \\
\hline $\begin{array}{l}\text { Flexion / extension of the } \\
\text { arms in the lying position }\end{array}$ & $79 \%$ & $\begin{array}{l}\text { Flexion / extension of the } \\
\text { arms in the lying position }\end{array}$ & $51 \%$ \\
\hline Standing long jump & $80 \%$ & Standing long jump & $63 \%$ \\
\hline Raising the torso & $81 \%$ & Raising the torso & $78 \%$ \\
\hline Running 3000 m & $54 \%$ & Running 3000 m & $41 \%$ \\
\hline
\end{tabular}

Note: the number of students who did not overcome the distance of $3000 \mathrm{~m}-3 \%$, the number of students who did not overcome the distance of $2000 \mathrm{~m}-5 \%$. 


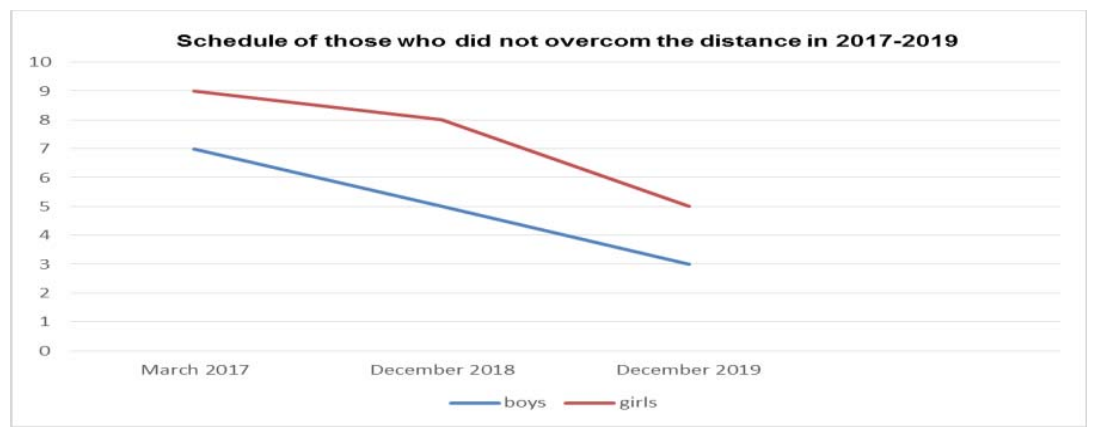

Fig. 1. The distance 2017-2019

Based on the results of control testing, the following conclusions can be drawn:

The changes introduced by the authors to physical culture lessons have been effective. The number of students who fulfilled the standards for the period of the experiment increased. After making adjustments to the load in the classroom, based on the results of intermediate tests, even more students fulfilled the proposed standards. In the very problematic testing-in running on $2000 \mathrm{~m}$ for girls and $3000 \mathrm{~m}$, the boys showed significant shifts in a positive context.

The number of students who were unable to overcome these distances completely decreased. Those students who covered the distance performed better than in the initial testing.
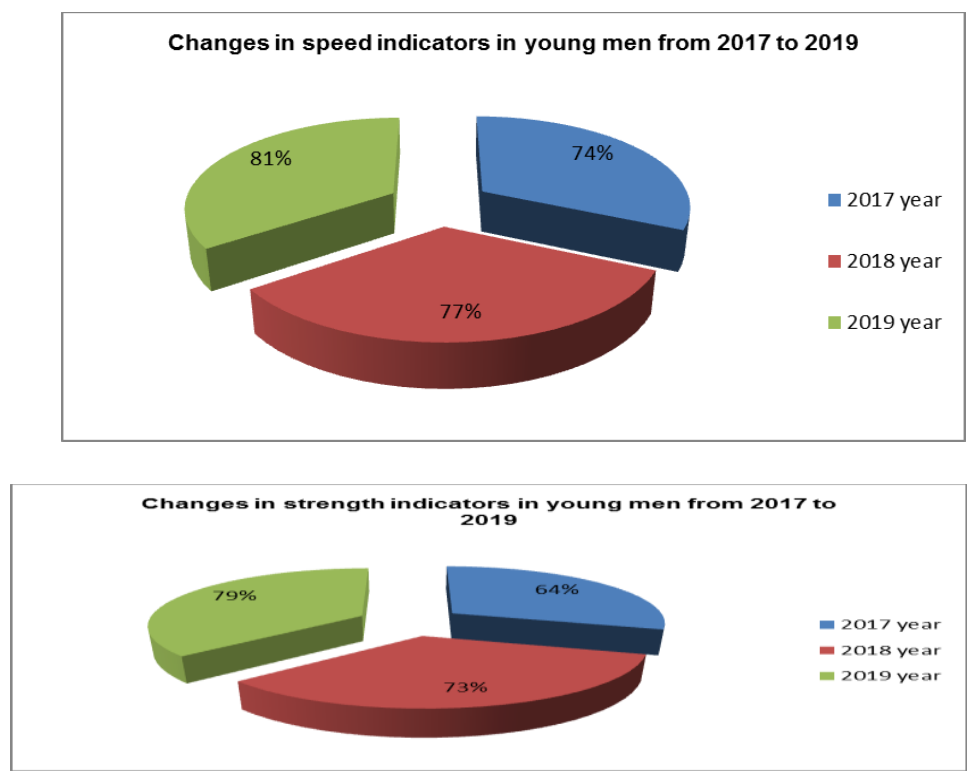

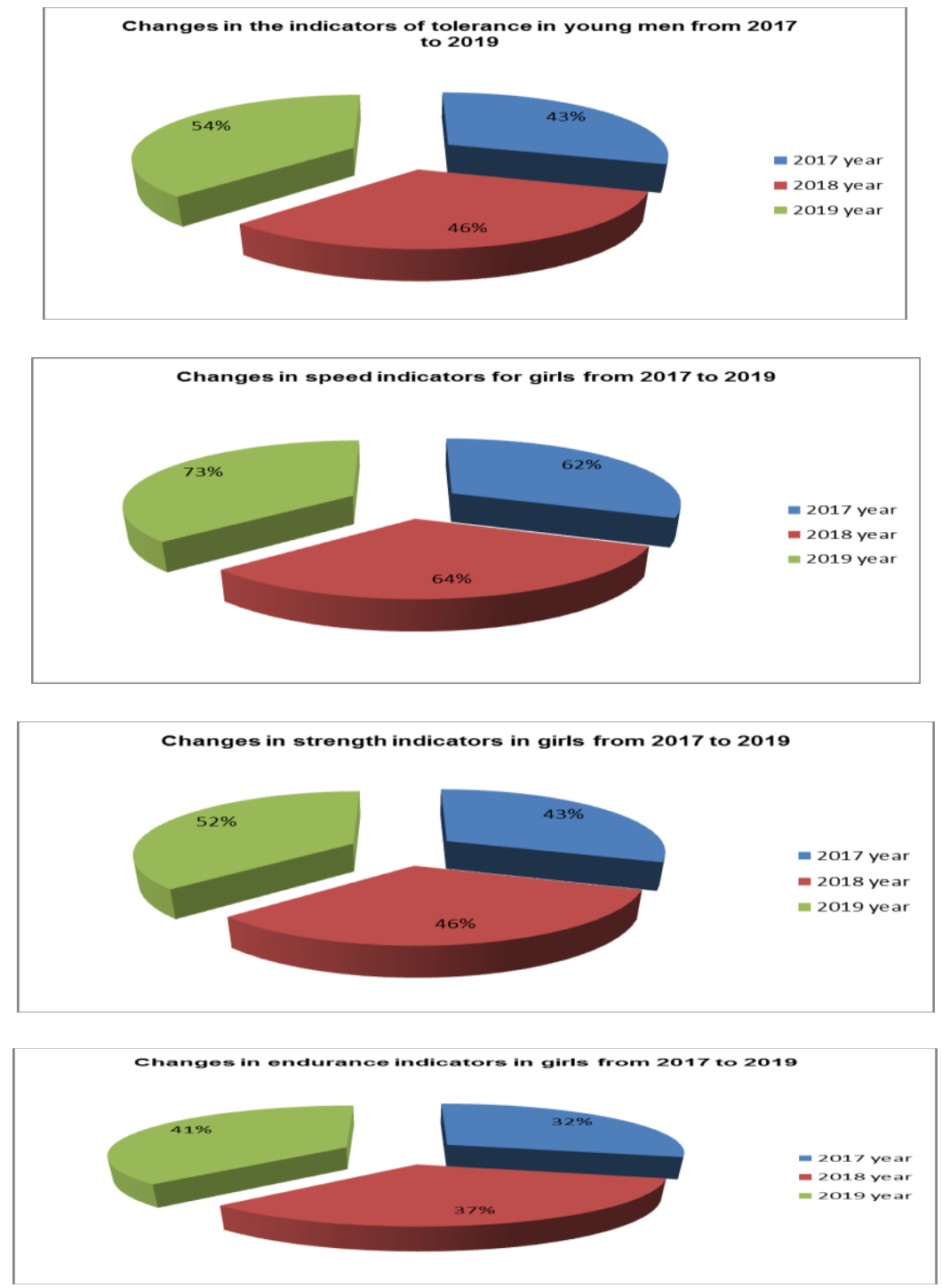

Fig. 2. The changes introduced by the authors to physical culture lessons have been effective

\section{Results}

The proposed and tested system of training specialists in the agro-industrial complex provides good indicators physical fitness of students.

Thus, it can be expected that the success of the program proposed by the authors will lead to an optimal balance of such qualities as speed, strength, endurance and will improve the adaptive potential of students.

It is assumed that the results research and methodological approaches can have significant applied interest in a professional context.

\section{Discussions}


By the general decision of the scientific and methodological council of the Department of Physical Education, the direction chosen by the authors was adopted and approved.

\section{Conclusions}

Submitted by brief summary of problems implementation by students of the Agroindustrial Faculty standards for strength, endurance, speed.

Considered the reasons for the need introduction of new methods and techniques for training student youth - future specialists - agrarians.

The authors of this article come to the conclusion that the proposed and tested system of training specialists in the agro-industrial complex provides good indicators physical fitness of students.

It is assumed that these results and methodological approaches may have significant applied interest in a professional context.

Thus, it can be expected that the success of the program proposed by the authors will lead to an optimal balance of such qualities as speed, strength, endurance and will improve the adaptive potential of students.

This article can be useful to everyone interested in the state of affairs in student sports, professionally applied physical culture.

The authors of the article express their gratitude to the rector of DSTU B.Ch. Meskhi for the opening and supervision of the TRP Testing Center at DSTU, which is so important for student youth, for the opportunity to professionally test student youth of the university, to the director of the Institute for Physical Culture and Sports, Mavropulo O.S. for valuable advice in the implementation of the study and the design of this article, to the director of the TRP Testing Center at DSTU Pogona Yulia Vladimirovna for the assistance provided during the study.

\section{References}

1. E.V. Khromin, All-Russian physical education and sport GTO complex: municipal management innovations, Theory and Practice of Physical Culture 1, 3-5 (2019)

2. A.V. Voronkov, Academic physical fitness rating by GTO complex tests, Theory and Practice of Physical Culture 5, 11 (2019)

3. T.J. Kauh, Building a culture of health through research: The role of the physical activity research center, Preventive Medicine 130, Article 105894 (2020)

4. S. G. Farris, Development and initial validation of the Exercise Sensitivity Questionnaire, Mental Health and Physical Activity 19, Article 100346 (2020)

5. P. S. Tandon, Short term impact of physical activity vs. sedentary behavior on preschoolers' cognitive functions, Mental Health and Physical Activity 15, 17-21 (2018)

6. A. Ivanova, Mathematical analysis of individual physical fitness test rates and functionality forecasts, Physical education: education, training 2(79), 53-56 (2019)

7. A. Ivanova, Adaptation and development of the physical culture and sports complex of the GTO in accordance with changes in society, the collection: Innovative transformations in the field of physical culture, sports and tourism. Collection of materials of the XXI All-Russian scientific and practical conference, 287-292 (2018)

8. P. S. Tandon, Short term impact of physical activity vs. sedentary behavior on preschoolers' cognitive functions, Mental Health and Physical Activity 15, 17-21 (2018) 
9. S. Rahimi, Long-term exercise from adolescence to adulthood reduces anxiety- and depression-like behaviors following maternal immune activation in offspring, Physiology \& Behavior 226, Article 113130 (2020)

10. T. Stepanova, Physical education and sports sector progress in rostov region, Theory and practice of physical culture 8, 98-99 (2018)

11. J. E. Simon, Health-related quality of life is decreased in middle-aged adults with chronic ankle instability, Journal of Science and Medicine in Sport 21(12), 1206-1209 (2018)

12. T. Wisbey-Roth, Prescribing exercise like the medicine it is, Journal of Science and Medicine in Sport 22, Supplement 1, 1 (2019)

13. B. S. Frank, Movement profile influences systemic stress and biomechanical resilience to high training load exposure, Journal of Science and Medicine in Sport, 22(1), 29-34 (2019)

14. J. L. Pryor, Intermittent exercise-heat exposures and intense physical activity sustain heat acclimation adaptations, Journal of Science and Medicine in Sport, 22(1), 117-122 (2019)

15. M. Shestakov, Content and ways of improving the physical education of students mastering management specialties, Scientific notes of the University. PF Lesgaft 5(147), 199-203 (2017)

16. N. Ryzhkin, T. Tumasyan, O. Brovashova, E. Nemtseva, A. Ivanova, Innovative Technologies in Science and Education (ITSE-2020), E3S Web of Conferences 210, 110 (2020) DOI: 10.1051/e3sconf/202021017009 